\title{
ИЗОТОПНЫЙ $\mathrm{Sr}-\mathrm{Nd}-\mathrm{Pb}-\mathrm{Hf-COСТАВ} \mathrm{ПОЗДНЕПАЛЕОЗОЙСКИХ}$ ГРАНИТОИДОВ ЦЕНТРАЛЬНОЙ ЧУКОТКИ
}

\author{
М. В. Лучицкая ${ }^{1, *}$, Б. В. Беляцкий ${ }^{2}$, Е. А. Белоусова ${ }^{3}$, Л. М. Натапов ${ }^{3}$ \\ Представлено академиком РАН Ю.М. Пущаровским 08.11.2016 г.
}

Поступило 03.10.2016 г.

\begin{abstract}
Представлены результаты изучения изотопного состава позднепалеозойских $\mathrm{Sr}-\mathrm{Nd}-\mathrm{Pb}-\mathrm{Hf}$-гранитоидов Центральной Чукотки на примере Киберовского, Куэквуньского массивов. Возраст гранитоидов этих массивов и гранитов из гальки конгломератов в основании перекрывающих нижнекаменноугольных отложений 351-363 млн лет (U-Pb-циркон, ТИМС, ВИМС, ЛА-ИСП-МС). Таким образом, гранитоидный магматизм соответствует по времени проявления тектоническим событиям элсмирской орогении в Арктическом регионе. Изотопный $\mathrm{Sr}-\mathrm{Nd}-\mathrm{Pb}-\mathrm{Hf}$-состав гранитоидов свидетельствует об участии мантийного и корового компонентов в формировании источника гранитных расплавов. Образование гранитоидов, вероятно, происходило в геодинамической обстановке континентальной окраины андийского типа при взаимодействии мантийных расплавов, образующихся при плавлении мантийного клина в надсубдукционных условиях, с континентальной корой.

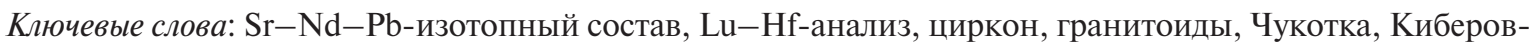
ский и Куэквуньский массивы.
\end{abstract}

DOI: https://doi.org/10.31857/S0869-5652485158-62

Исследование петро-геохимического и изотопного $\mathrm{Sr}-\mathrm{Nd}-\mathrm{Pb}$-состава гранитоидов и $\mathrm{Lu}-\mathrm{Hf}-\mathrm{aнa}-$ лиз содержащихся в них цирконов позволяют прояснить петрогенезис пород, установить геохимические характеристики источников гранитоидных магм, проследить главные события в их магматической эволюции и оценить степень мантийно-корового взаимодействия при их образовании. Данные об изотопном $\mathrm{Sr}-\mathrm{Nd}-\mathrm{Pb}$-составе гранитоидов Чукотских мезозоид очень фрагментарны и касаются преимущественно мезозойских редкометальных гранитоидов [1, 2]. Для позднепалеозойских гранитоидов возраст надёжно обоснован $\mathrm{U}-\mathrm{Pb}$-датировками цирконов (ВИМС, ТИМС) [3, 4]; впервые изучен изотопный $\mathrm{Sr}-\mathrm{Nd}-\mathrm{Pb}$-состав и проведён $\mathrm{Lu}-\mathrm{Hf}$-анализ цирконов, результаты которых представлены в нашей работе.

В пределах Центральной Чукотки позднепалеозойские гранитоиды слагают Киберовский и Куэквуньский массивы, приуроченные к центральным частям соответственно Куульского и Куэквуньского поднятий Анюйско-Чукотской складчатой системы (рис. 1), в которых вскрыты образования палеозой-

\footnotetext{
1 Геологический институт

Российской Академии наук, Москва

2 Всероссийский научно-исследовательский геологический институт им. А.П. Карпинского, Санкт-Петербург

${ }^{3}$ GEMOC ARC National Key Centre, Department of Earth and Planetary Sciences, Macquarie University, Sydney, Australia

*E-mail: luchitskaya@ginras.ru
}

ского чехла Чукотского микроконтинента. Гранитоиды Киберовского массива прорывают терригенные и карбонатно-терригенные породы девона, и их галька присутствует в конгломератах в основании нижнекаменноугольных терригенно-карбонатных отложений. Киберовский массив сложен преимущественно биотитовыми гранитами, гранодиоритами, переходы между которыми постепенные; в меньшей степени присутствуют лейкограниты, аляскиты, субщелочные граниты. Гранитоиды Куэквуньского массива прорывают осадочные и метаморфические комплексы девона-карбона и превращены в очковые гнейсы или гранито-гнейсы, которые по химическому составу соответствуют кварцевым монцодиоритам, сиенитам, гранодиоритам, гранитам, лейкогранитам.

На основании геохронологических исследований гранитоидов Киберовского, Куэквуньского массивов, а также гранитоидов из гальки конгломератов в основании каменноугольных отложений был установлен их раннекаменноугольный возраст 352 359 млн лет (U-Pb-циркон, ТИМС, ВИМС [3, 5]), соответствующий проявлениям тектонических событий элсмирской орогении в Арктическом регионе.

Петрографический состав и петро-геохимические характеристики гранитоидов Киберовского, Куэквуньского массивов и гранитов из гальки указывают на их принадлежность к гранитам I-типа, включая и их высокодифференцированные разности [3]. 

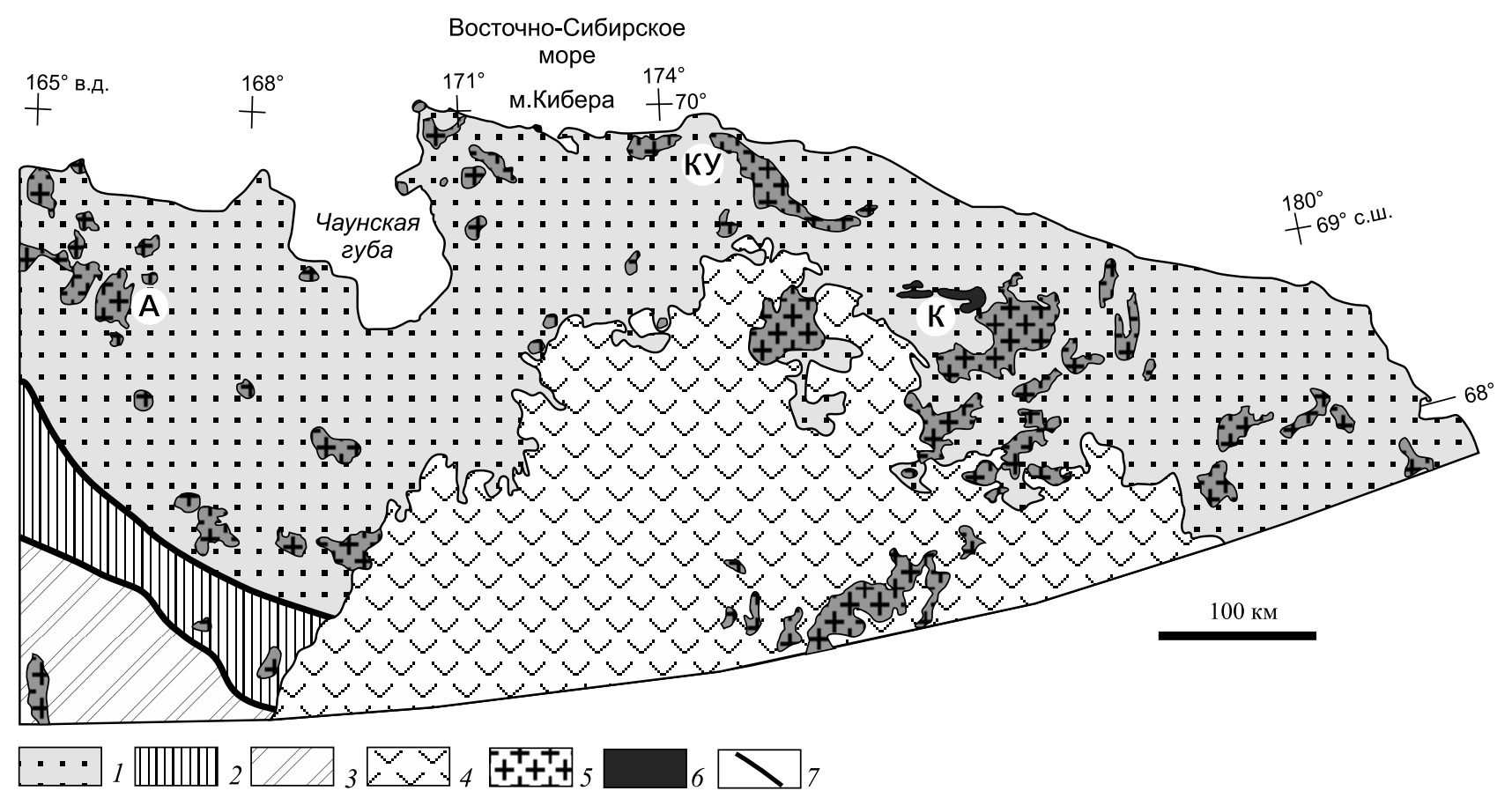

Рис. 1. Схема геологического строения Центральной Чукотки ([10] с изменениями). 1 - Анюйско-Чукотская складчатая система: 2 - Южно-Анюйская сутурная зона; 3 - Алазейско-Олойская складчатая система; 4 - Охотско-Чукотский вулканический пояс; 5, 6- гранитоиды: 5 - меловые; 6 - позднепалеозойские; 7 - разрывные нарушения. Буквы - поднятия: А - Алярмаутское, КУ - Куульское, К - Куэквуньское.

Изотопный состав $\mathrm{Sr}, \mathrm{Nd}, \mathrm{Pb}$-гранитоидов был определён в Центре изотопных исследований ВСЕГЕИ (г. С.-Петербург) на термоионизационном масс-спектрометре TRITON (ТИМС) по методике, описанной в [6]. Изучение изотопной $\mathrm{Lu}-\mathrm{Hf}$ системы цирконов было проведено в Центре GEMOC Университета Макуори (Сидней) in situ с помощью ультрафиолетового лазера New Wave UP $213 \mathrm{~nm}$, совмещённого с мультиколлекторным массспектрометром с индуктивно-связанной плазмой $\mathrm{Nu}$ Plasma (ИСП-МС). Описание технических деталей, методических приёмов и констант, используемых для вычислений єНf и модельных возрастов $\left(T_{\mathrm{DM}}^{\mathrm{C}}\right)$, приведено в [7].

Начальное ${ }^{143} \mathrm{Nd} /{ }^{144} \mathrm{Nd}$ в изученных гранитоидах 0,512037-0,512134, а $\varepsilon \mathrm{Nd}(T)$ от $-0,95$ до $-2,83$ (рис. 2a). Модельные одностадийные, двустадийные возрасты гранитоидов обоих массивов и гранитов из гальки достаточно близки и соответствуют интервалам 1034-1148, 1203-1300 млн лет мезопротерозоя. Исключение составляют аляскиты Киберовского массива, которые имеют более древний палеопротерозойский одностадийный возраст (2218 млн лет) и несколько более древний, чем в остальных гранитоидах, мезопротерозойский двухстадийный возраст (1361 млн лет).

Гранитоиды обоих массивов имеют сравнительно высокие величины начального ${ }^{87} \mathrm{Sr} /{ }^{86} \mathrm{Sr}$ от 0,705889 до 0,707845 (рис. 2б). Минимальные значения характерны для монцонитов из включений в гранитах Киберовского массива, максимальные - для гранодиоритов того же массива. Граниты из гальки резко выделяются нереально низкими величинами начального ${ }^{87} \mathrm{Sr} /{ }^{86} \mathrm{Sr}(0,695045)$, что определяется завышенным $\mathrm{Rb} / \mathrm{Sr}$ за счёт избытка $\mathrm{Rb}$ или общей диспропорции $\mathrm{Rb}, \mathrm{Sr}$ вследствие позднего выветривания слюд и подвижности $\mathrm{Rb}-\mathrm{Sr}$-системы в гипергенных условиях.

Изотопный состав $\mathrm{Pb}$ в гранитоидах Киберовского массива варьирует в широких пределах: ${ }^{206} \mathrm{~Pb} /{ }^{204} \mathrm{~Pb}=18,8615-20,1301 ;{ }^{207} \mathrm{~Pb} /{ }^{204} \mathrm{~Pb}=$ $=15,6015-15,7134 ;{ }^{208} \mathrm{~Pb} /{ }^{204} \mathrm{~Pb}=38,4355-39,3947$. Разброс этих отношений для гранитоидов Куэквуньского массива менее значительный: ${ }^{206} \mathrm{~Pb} /{ }^{204} \mathrm{~Pb}=$ $=19,0710-19,4393 ;{ }^{207} \mathrm{~Pb} /{ }^{204} \mathrm{~Pb}=15,6105-15,6425$; ${ }^{208} \mathrm{~Pb} /{ }^{204} \mathrm{~Pb}=39,5055-40,1312$. А наименее радиогенный состав Рb имеют граниты из гальки: ${ }^{206} \mathrm{~Pb} /{ }^{204} \mathrm{~Pb}=$ $=18,6909 ;{ }^{207} \mathrm{~Pb} /{ }^{204} \mathrm{~Pb}=15,6157 ;{ }^{208} \mathrm{~Pb} /{ }^{204} \mathrm{~Pb}=38,7637$.

В координатах ${ }^{207} \mathrm{~Pb} /{ }^{204} \mathrm{~Pb}-{ }^{206} \mathrm{~Pb} /{ }^{204} \mathrm{~Pb}$ (рис. 2 в) фигуративные точки изотопного состава $\mathrm{Pb}$ гранитоидов Киберовского, Куэквуньского массивов и гранитов из гальки, пересчитанного на возраст образования (350 млн лет назад), расположены на линии модельной эволюции изотопного состава $\mathrm{Pb}$ в орогене, за исключением образца монцонита из включения в гранитах Киберовского массива, 
(a)

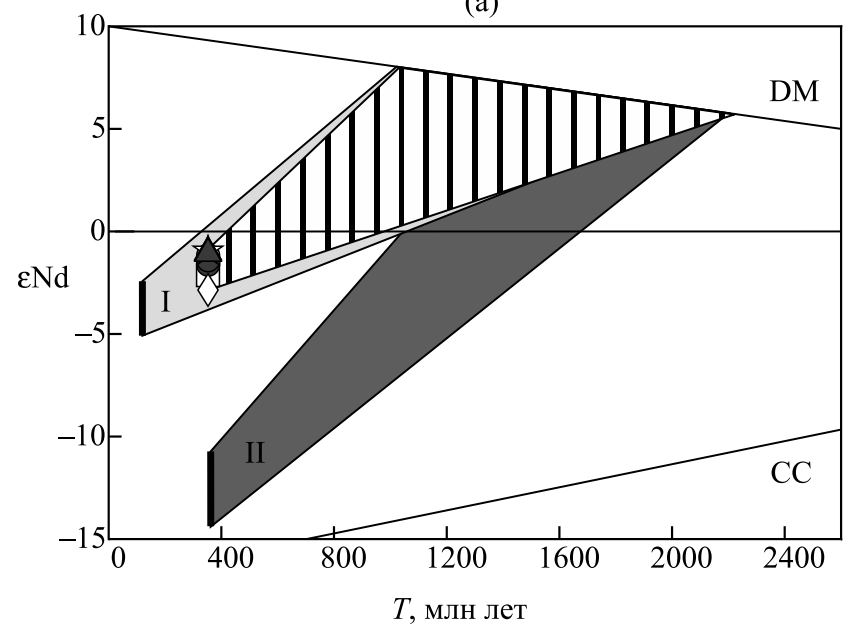

(B)

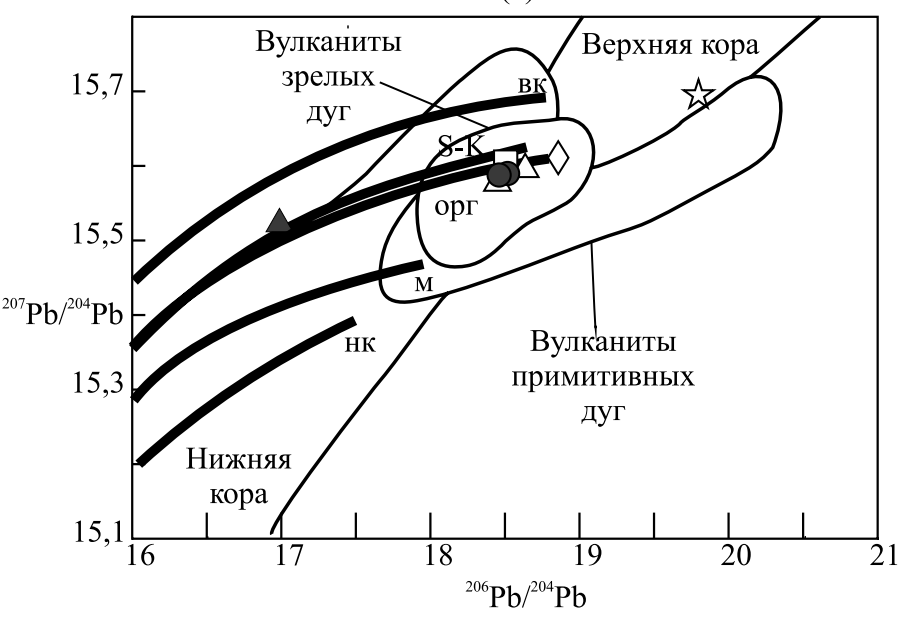

(б)

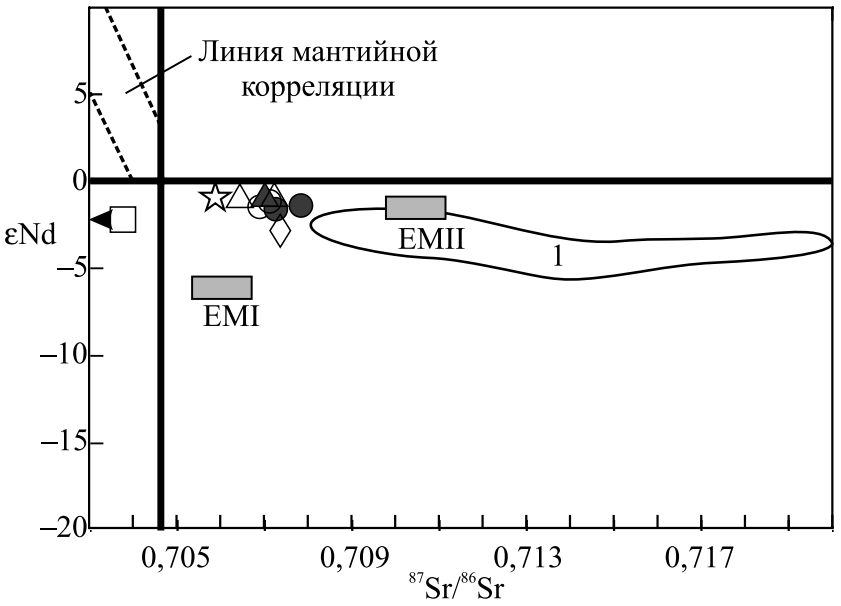

(г)

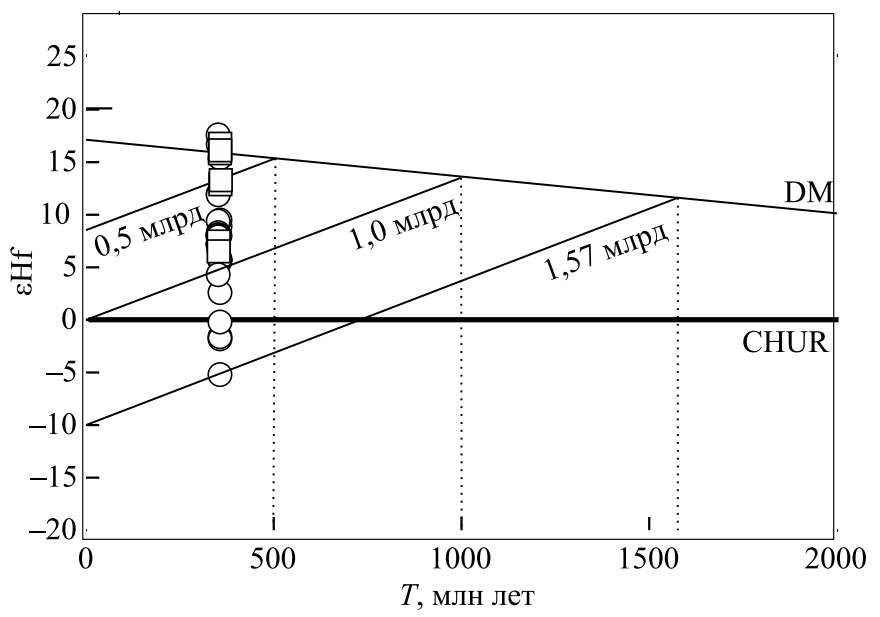

\section{$\begin{array}{lllllll} & 02 & \Delta & \Delta & \Delta 4 & \Delta 5 & \Delta 6 \quad \square 7\end{array}$}

Рис. 2. Диаграммы $\varepsilon \mathrm{Nd}(T)$ 一 время (а), $\varepsilon \mathrm{Nd}(T)-{ }^{87} \mathrm{Sr} /{ }^{86} \mathrm{Sr}$ (б), ${ }^{207} \mathrm{~Pb} /{ }^{204} \mathrm{~Pb}-{ }^{206} \mathrm{~Pb} /{ }^{204} \mathrm{~Pb}\left(\right.$ в),${ }^{207} \mathrm{~Pb} /{ }^{204} \mathrm{~Pb}-{ }^{206} \mathrm{~Pb} /{ }^{204} \mathrm{~Pb}($ г), и $\mathrm{EHf-время} \mathrm{для} \mathrm{гранитоидов} \mathrm{Киберовского,} \mathrm{Куэквуньского} \mathrm{массивов,} \mathrm{гранитов} \mathrm{из} \mathrm{гальки} \mathrm{конгломератов} \mathrm{в} \mathrm{осно-}$ вании нижнекаменноугольных отложений. DM - деплетированная мантия; СC - континентальная кора; ЕМI, EMII - модельные мантийные компоненты: EMI - обогащённая мантия с высоким Rb/Sr, EMII — обогащённая мантия с высоким $\mathrm{Nd} / \mathrm{Sm}$. Линии на (в) соответствуют эволюции изотопного состава Рb в различных модельных резервуарах: ВК - верхней континентальной коре, ОРГ - орогене, М - истощённой мантии, НК - нижней континентальной коре. Поля модельных источников: нижне- и верхнекоровых, зрелых и примитивных островных дуг. I - поле гранитоидов Алярмаутского поднятия, II - поле позднепалеозойских гранитоидов террейна Юкон-Танана. 1-4 - гранитоиды Киберовского массива: 1 - гранит, 2 - гранодиорит, 3 - монцонит из включения, $4-$ аляскит; 5, 6 - гранитоиды Куэквуньского массива: 5 - гранодиорит, 6 - кварцевый монцодиорит; 7 - гранит из гальки.

точка состава которого находится между линиями эволюции изотопного состава Рb орогена и верхней коры. Такое расположение точек изотопного состава проанализированных образцов гранитоидов может свидетельствовать о смешении мантийного и корового материала при образовании источника гранитных магм. При сравнении в тех же координатах положения полей нижне- и верхнекоровых модельных источников, а также зрелых и примитивных островных дуг видно, что точки изотопных составов $\mathrm{Pb}$ гранитоидов обоих массивов и гранитов из гальки сосредоточены преимущественно в поле пород зрелых островных дуг (рис. 2в).

Анализ изотопной Lu-Hf-системы цирконов из гранитов Киберовского массива выявил широкий разброс величин ${ }^{176} \mathrm{Hf} /{ }^{177} \mathrm{Hfi}$ и $\varepsilon \mathrm{Hf}=0,282721-$ 0,283418 от + 16,7 до -5,2 для гранитов Киберовского массива. Интервалы этих величин для циркона из гранитов гальки несколько меньше: 0,2824150,283683, а عНf имеет только положительные значения: от +16,7 до +6,5. Одностадийные модельные Hf-возрасты для гранитов Киберовского массива 
и гальки обнаруживают практически одинаковый разброс, а сам модельный возраст совпадает с возрастом гранитов: 300-740 и до 720 млн лет соответственно. Однако максимальные двухстадийные модельные возрасты ( $T_{\mathrm{DM}}^{\mathrm{C}}$ ) различаются: 1,57 и 0,88 млрд лет соответственно. Большая часть фигуративных точек проанализированных цирконов на диаграмме $\varepsilon \mathrm{Hf}-$ возраст расположена между линиями эволюции мантии хондритового состава CHUR $(\varepsilon H f=0)$ и обеднённой - DM (рис. 2г), что указывает на присутствие материала мантийного происхождения при формировании источника гранитных расплавов. Отрицательные величины єНf, характерные только для цирконов из гранитов Киберовского массива, указывают на участие древнего (не древнее мезопротерозойского) корового материала в субстрате, при плавлении которого сформировались гранитные магмы.

Таким образом, представленные данные об изотопном $\mathrm{Sr}-\mathrm{Nd}-\mathrm{Pb}-\mathrm{Hf}$-составе гранитоидов Киберовского, Куэквуньского массивов и гранитов из гальки свидетельствуют об участии мантийного и корового компонентов в формировании источника гранитных расплавов, на что указывают небольшие отрицательные величины $\varepsilon \mathrm{Nd}(T)$, промежуточные между гранитами I- и S-типа величины начального ${ }^{87} \mathrm{Sr} /{ }^{86} \mathrm{Sr}$, широкие вариации значений отношений изотопов $\mathrm{Pb}$ и $\varepsilon \mathrm{Hf}$ в цирконах гранитоидов. Однои двухстадийные Nd- и Нf-модельные возрасты гранитоидов предполагают мезопротерозойский-палеопротерозойский возраст корового протолита. Мезопротерозойские унаследованные цирконы присутствуют в неопротерозойских гранитоидах метаморфического фундамента, который обнажается на о. Врангеля [8].

Совокупность петрографических, петро-геохимических и изотопных данных позволяет предполагать, что формирование гранитоидов происходило в геодинамической обстановке континентальной окраины андийского типа при взаимодействии мантийного вещества, образующегося при плавлении мантийного клина в надсубдукционных условиях, с континентальной корой. Полученные результаты и представленная интерпретация хорошо согласуются с реконструкцией окраинно-континентальной магматической дуги позднедевонского-раннекаменноугольного возраста на южной окраине докембрийского блока Беннет-Барровия или Арктида (фундамента микроконтинента Чукотка-Арктическая Аляска), коллизия которого с окраиной Северо-
Американского кратона в позднем силуре-раннем девоне привела к элсмирскому орогенезу в Северной Аляске и Канадских Арктических о-вах [9].

Источник финансирования. Работа выполнена при финансовой поддержке РФФИ (грант № 17-0500795).

\section{СПИСОК ЛИТЕРАТУРЫ}

1. Ефремов C.В. Редкометальные гранитоиды Чукотки. Геохимия, источники вещества, модели образования: Автореф. дис. д-ра геол.-минерал. наук. Иркутск, 2012. 40 с.

2. Алексеев В.И. Литий-фтористые граниты Дальнего Востока. СПб., 2014. 244 с.

3. Лучицкая М.В., Соколов С.Д., Котов А.Б., Натапов Л.М., Белоусова Е.А., Катков С.М. Позднепалеозойские гранитоиды Чукотки: особенности состава, обоснование возраста и положение в структуре арктического региона России // Геотектоника. 2015. № 4. С. 3-29.

4. Lane L.S., Cecile M.P., Gehrels G.E., Kos'ko M.K., Layer P.W., Parrish R.R. Devonian-Carboniferous Paleogeography and Orogenesis, Northern Yukon and Adjacent Arctic Alaska // Canad. J. Earth Sci. 2015. V. 52. P. 147-160.

5. Катков С.М., Лучицкая М.В., Котов А.Б., Сальникова Е.Б., Яковлева С.З. О возрасте гранитных интрузий Анюйско-Чукотской складчатой системы // ДАН. 2013. Т. 450. № 2. С. 193-198.

6. Сущевская Н.М., Мигдисова Н.А., Антонов А.В., Крымский Р.Ш., Беляцкий Б.В., Кузьмин Д.В., Бычкова Я.В. Геохимические особенности лампроитовых лав четвертичного вулкана Гауссберг (Восточная Антрактида) - результат влияния мантийного плюма Кергелен // Геохимия. 2014. № 12. С. 1079-1098.

7. Кузнецов Н.Б., Натапов Л.М., Белоусова Е.А., $O$ 'Рейли $C$. Первые результаты изотопного анализа детритных цирконов поднятия Енганэ-Пэ (Полярный Урал): попытка определения палеотектонической позиции протоуралид-тиманид // ДАН. 2009. Т. 426. № 4. С. 504-510.

8. Лучицкая М.В., Сергеев С.А., Соколов С.Д., Тучкова М.И. Неопротерозойские гранитоиды острова Врангеля // ДАН. 2016. Т. 469. № 2. С. 195-198.

9. Natal'in B., Amato J.M., Toro J., Wright J.E. Paleozoic Rocks of Northern Chukotka Peninsula, Russian Far East: Implications for the Tectonic of Arctic Region // Tectonics. 1999. V. 18. № 4. P. 977-1003.

10. Тибилов И.В., Черепанова И.Ю. Геология севера Чукотки - современное состояние и проблемы. М.: Геос, 2001. 94 c. 


\title{
$\mathrm{Sr}-\mathrm{Nd}-\mathrm{Pb}-\mathrm{Hf}$ ISOTOPIC COMPOSITION \\ OF LATE PALEOZOIC GRANITOIDS OF CENTRAL CHUKOTKA
}

\author{
M. V. Luchitskaya, B. V. Belyatsky, E. A. Belousova, L. M. Natapov
}

Presented by Academician of the RAS D.Yu. Pushcharovsky November 8, 2016

\section{Received October 3, 2016}

Results of the study of $\mathrm{Sr}-\mathrm{Nd}-\mathrm{Pb}-\mathrm{Hf}$ isotopic composition of Late Paleozoic granitoids of Central Chukotka are represented on the example of Kibera and Kuekvun plutons. The age of granitoids of these plutons and granites from pebbles in conglomerates in the base of overlying Lower Carboniferous deposits is $351-363 \mathrm{Ma}(\mathrm{U}-\mathrm{Pb}$ zircon, TIMS, SIMS, LA-ICP-MS). Thus, granitoid magmatism corresponds in time to tectonic events of Elsmerian orogeny in Arctic region. $\mathrm{Sr}-\mathrm{Nd}-\mathrm{Pb}-\mathrm{Hf}$ isotopic composition of granitoids indicate participation of mantle and crustal components in the source of granite melts. Granitoids formation probably occurred in geodynamic setting of Andean type continental margin during the interaction between mantle melts, forming at the mantle wedge melting in suprasubduction conditions, and continental crust.

Keywords: $\mathrm{Sr}-\mathrm{Nd}-\mathrm{Pb}$ isotopic composition, $\mathrm{Lu}-\mathrm{Hf}$ analysis, zircon, granitoids, Chukotka, Kibera and Kuekvun plutons. 